\title{
THE ROLE OF AGRIBUSINESS IN STIMULATING ON-FARM INVESTMENTS - CASE-STUDY OF THE ARMENIAN DAIRY SECTOR ${ }^{1}$
}

\author{
Liesbeth Dries ${ }^{1}$, Matthew Gorton ${ }^{2}$, John White ${ }^{3}$, Vardan Urutyan ${ }^{4}$, Gagik Sardaryan ${ }^{5}$ \\ ${ }^{1}$ Wageningen University, the Netherlands \\ ${ }^{2}$ Newcastle University Business School, UK \\ ${ }^{3}$ University of Plymouth, UK \\ ${ }^{4}$ Armenian State Agrarian University, Armenia \\ ${ }^{5}$ Centre for Agribusiness and Rural Development, Armenia
}

\begin{abstract}
This paper analyses the impact on investments of contractual arrangements between farms and agribusiness in the Armenian dairy sector. Our empirical evidence is based on a unique survey of 300 Armenian dairy farms. The dairy sector is of particular importance as it provides vital employment and income, in an environment of weak social security and scarce job opportunities. Furthermore, milk production is predominantly organized in small-scale farms, which are most likely to be affected by adversarial financial conditions and limited in their opportunities to raise resources to invest. The results show that a large share of milk producers in Armenia is actively investing to upgrade their farm business. Furthermore, investment activity is not limited to large dairy farmers as over $30 \%$ of respondents with less than eight cows have made dairy-specific investments. We find that the linkages between farms and agribusiness - and more specifically the support programs that agribusiness firms offer to their suppliers - have been crucial in stimulating this restructuring process at the farm level. Interestingly, farmers with a more exclusive relationship to the buyer and farmers that deliver to more internationally oriented buyers are more likely to receive support. On the other hand, buyers that operate in a more competitive market are less likely to provide support to their suppliers. These findings have interesting policy implications. On the one hand, our results point to the gains that can be made from openness to international firms. On the other hand, the negative competition effect indicates that buyers are unable to enforce repayment of the provided farm services in an environment where a lot of buyers are competing for the same supply. Policy makers should look at ways of improving the enforcement capability of dairy companies under these circumstances.
\end{abstract}

Keywords: Dairy, on-farm investments, vertical coordination, Armenia

\section{Introduction}

Agricultural credit and rural finance problems are important constraints on restructuring and growth in transition countries. Financial resources can come from own resources and from formal or informal loans. However, cash flow and profitability problems have constrained both types of financing. This has induced political pressure for governments to intervene. In many transition countries this has resulted in the introduction of subsidies and loan guarantee programs. Not only policy reforms but also private companies have contributed to overcoming financial constraints. Agribusiness restructuring and investments upand downstream from the farms have helped to reduce farm finance constraints.

This paper analyses the impact on investments of contractual arrangements between farms and agribusiness in the Armenian dairy sector. Our empirical evidence is based on a unique survey of 300 Armenian dairy farms. Data were collected in 2006 through a random survey in the main dairy regions. Agriculture remains the backbone of the economy in Armenian rural areas where the sector accounts for over 50 per cent of gainful employment. Rural welfare is therefore inherently linked to the fortunes of agriculture. The dairy sector is of particular importance as it provides vital employment and income, in an environment of weak social security and scarce job opportunities. Furthermore, milk production is predominantly organized in small-scale farms, which are most likely to be affected by adversarial financial conditions and limited in their opportunities to raise resources to invest.

The results show that a large share of milk producers in Armenia is actively investing to upgrade their farm business. Furthermore, investment activity is not limited to large dairy

1 The data used in this paper were collected in the SIDCISA (Supporting the International Development of CIS Agriculture) research project. This project was funded by EU INTAS. 
farmers as over $30 \%$ of respondents with less than eight cows have made dairy-specific investments. Finally, we find that the linkages between farms and agribusiness have been crucial in stimulating this restructuring process at the farm level.

The remainder of this paper is organized as follows. We first provide information on the dataset and the data collection process. Next, we discuss descriptive statistics on on-farm investments and the sources of agricultural finance that are employed in the Armenian dairy sector. Finally, we introduce a basic investment model and analyze the determinants of on-farm investments. We pay special attention to the role played by the dairy processor in stimulating dairy-specific investments. A discussion of the main results and final remarks conclude the paper.

\section{Materials and methods}

Data collection was conducted in 2006 and focused on having a better understanding of the supply chain relationships of commercial milk producers, paying particular attention to the linkages between vertical relationships and the potential to influence on-farm decisions. Given this objective, the population of interest was defined as primary producers which sold cows' milk to another supply chain actor. Therefore farmers without dairy cows, those who did not sell any of the milk produced or who processed all milk into cheese or other dairy products (i.e. did not sell any raw milk) were excluded from the study. Given the objective of the study these restrictions are justified but it means that our sample cannot be directly compared to official data on the structure of milk production.

To obtain the sample a quota of 300 responses was set with the intention of including a representative cross-section of commercial dairy farms, including both household producers if they marketed their output and agricultural companies. Respondents were drawn from all regions (Marzes) which have significant commercial milk production, based on proportions given from statistical data on milk production. The cross-section of farm respondents was identified from contacts with national statistical agencies, local and regional authorities, village majors, local livestock experts and agricultural agencies. Data were collected concerning: farm growth, prices, yields, investment, collaboration with other farmers, the nature of and satisfaction with relationships with their main buyer and non-price aspects of contracts. The data set by herd size is presented in Table 1. In contrast to other CIS countries - e.g. Ukraine - corporate farms with herds of more than 200 milking cows are absent from Armenia. None of the sampled farms in Armenia were registered entities and all of them are legally classified as individual farmers. ${ }^{2}$
Table 1: Farm size distribution in the sample (based on number of milking cows)

\begin{tabular}{|c|c|}
\hline No of milking cows & No of farms in the sample \\
\hline$<5$ & 20 \\
\hline 5 & 50 \\
\hline 6 to 9 & 111 \\
\hline 10 to 19 & 77 \\
\hline 20 to 49 & 29 \\
\hline$>49$ & 13 \\
\hline Total & 300 \\
\hline
\end{tabular}

Source: Survey data and Gorton et al. (2007)

\section{On-farm investments and agricultural finance in Armenia}

Before presenting summary statistics related to on-farm investments, we briefly describe the vertical relationships between milk producers and downstream buyers in the Armenian dairy supply chain. Dairy processors are the most common main buyers of milk from farmers. In Armenia over three quarters of farms sell directly to dairy processors. Another $20 \%$ of dairy farms sells through a co-operative. The remainder of milk is collected by intermediaries: dairy logistics or collecting firms (Gorton et al. 2007). The majority of dairy farmers sells milk based on a contractual arrangement: $38 \%$ has signed a written contract with the milk buyer; $36 \%$ sells milk based on an oral contract; only a quarter of the sampled farms has not entered into a contractual agreement (Gorton et al. 2007).

The institutional arrangements that exist between milk buyers and sellers are often much more extensive than simple agreements on price, volumes and delivery conditions. Table 2 shows that vertical relationships in the Armenian dairy sector also involve a wide range of support measures. The most prevalent types of support are prompt payments and quality control, which are received by over 80 per cent of farms. Around 30 per cent of farmers in Armenia also receive credit from their main buyer.

Figure 1 provides evidence of the investment activities of the farms that are included in the sample. A large share of respondents indicate that they have made on-farm investments in the past five years. Also, looking specifically at dairy-specific investments, a total of 120 respondents out of 300 claim to have made investments in cooling tanks, milk lines, cows and so on.

An interesting issue is whether there exists a link between investment behaviour and size of the farm. Figure 2 presents data on investments on farms of different. In general we notice a positive correlation between farm size and propensity to invest, meaning that larger farms have made relatively more

${ }^{2}$ Commencing from 2009, Armenian farms will have to be registered and thus taxed on their activities. 
Table 2: Share of farms receiving support from their main buyer

\begin{tabular}{|l|c|}
\hline \multicolumn{1}{|c|}{ Support measure } & \% farms receiving support \\
\hline Quality control & 87.7 \\
\hline Prompt payments & 82.7 \\
\hline Guaranteed Prices & 46.7 \\
\hline Market access & 40.0 \\
\hline Credit & 30.7 \\
\hline Veterinary support & 23.7 \\
\hline Transportation & 20.3 \\
\hline Physical inputs & 16.3 \\
\hline Business and financial management support & 4.0 \\
\hline Farm loan guarantees & 4.0 \\
\hline Specialist storage & 2.0 \\
\hline Machinery & 1.7 \\
\hline Investment loans & 1.7 \\
\hline
\end{tabular}

Source: Survey data and Gorton et al. (2007)

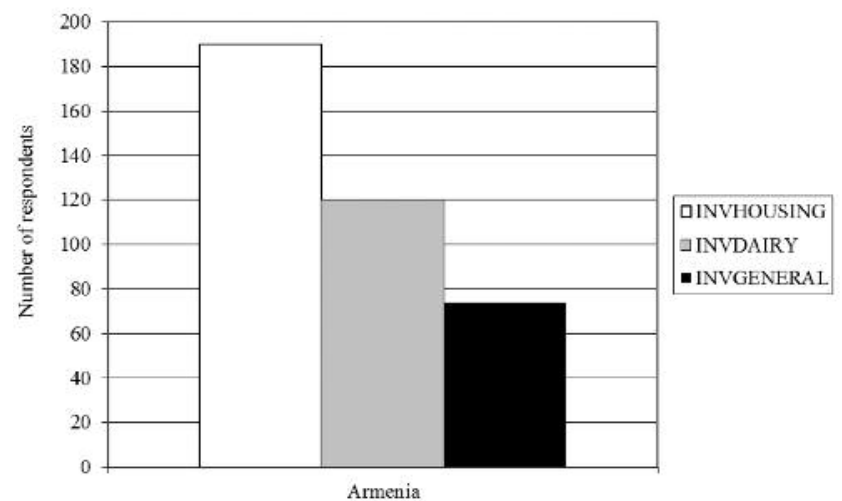

Figure 1: Investments in the past five years on surveyed farms (INVHOUSING includes investments in animal housing facilities: building, enlarging or modernizing stalls sheds and herdsman's camps. INVDAIRY includes dairy-specific investments in new calves and cows, milk lines, cooling tanks and fodder mixers. INVGENERAL are investments that are not specifically related to milk production such as buying new land, pastures, investments in fences and general agricultural equipment)

Source: Survey data

investments in the past five years than small farms (with a small farm being defined as having less than 7 cows).

Finally, we present data on expected future investments by farmers in Armenia (figure 3). The main categories in which respondents are planning to invest are: animal housing, buying new land, buying new cows and improving pastures.

\section{Vertical relationships and on-farm investments in the Armenian dairy sector}

\subsection{Determinants of farm support programs}

In this section we will determine the role played by dairy processors' support programs in stimulating on-farm

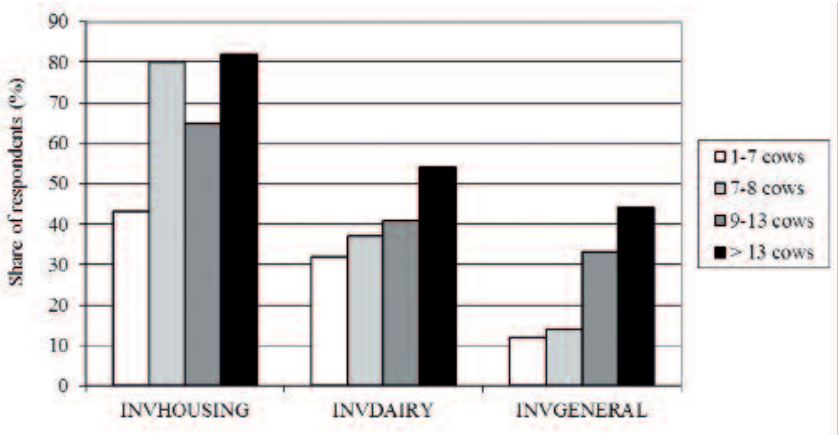

Figure 2: Investments and farm size distribution of surveyed farms ((INVHOUSING includes investments in animal housing facilities: building, enlarging or modernizing stalls sheds and herdsman's camps. INVDAIRY includes dairy-specific investments in new calves and cows, milk lines, cooling tanks and fodder mixers. INVGENERAL are investments that are not specifically related to milk production such as buying new land, pastures, investments in fences and general agricultural equipment)

Source: Survey data

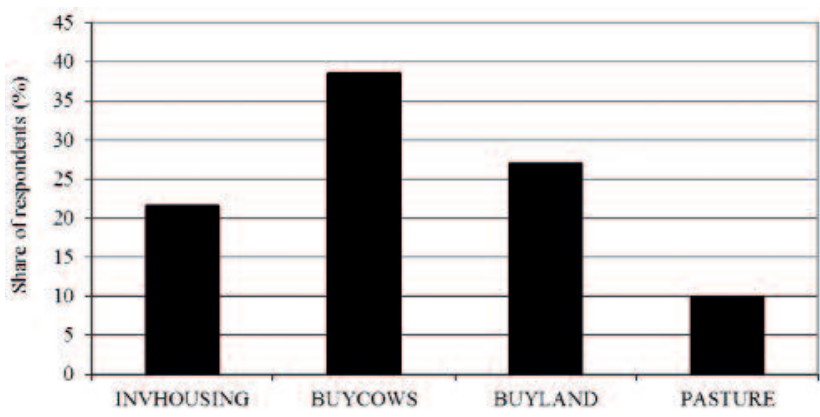

Figure 3: Expected future investments (INVHOUSING includes investments in animal housing facilities: building, enlarging or modernizing stalls sheds and herdsman's camps. INVDAIRY includes dairy-specific investments in new calves and cows, milk lines, cooling tanks and fodder mixers. INVGENERAL are investments that are not specifically related to milk production such as buying new land, pastures, investments in fences and general agricultural equipment)

Source: Survey data

investments. Before we turn to the investment model, we want to gain insight in the elements that determine access to support programs. Support programs are offered as part of a vertical relationship between suppliers and buyers of milk. We will therefore focus on the characteristics of this relationship to identify the factors that make it more or less likely that farmers have access to support programs. The relationship that we estimate is the following:

$\operatorname{SUPPORT}_{i}=\beta_{\mathbf{0}}+\beta_{\mathbf{1}}$ BUYER $_{i}+\beta_{\mathbf{2}}$ CONTROL $_{i}+\varepsilon_{i}$

where SUPPORT is a measure of access to farm support programs, BUYER is a vector of variables that characterize the vertical relationship between the milk producer and the buyer; CONTROL is a vector of control variables; and finally $\varepsilon$ is the error term.

SUPPORT is a dummy taking the value of one if the farm household received support from their main buyer of milk. The support categories that are included are: credit; 
investment loans; farm loan guarantees; physical inputs. BUYER includes a number of variables that identify the vertical relationship between the milk producer and the main buyer of milk. SHARE includes the share of the farm's total milk production that is sold to the main buyer. We expect that a more exclusive relationship with the main buyer (i.e. a higher share of milk sold to this trading partner leads to a stronger vertical relationship and) is a proxy for trust and the reputation effect. We expect SHARE to have a positive impact on the likelihood of farm assistance programs. Another factor that can affect the chances of receiving support through the buyer-supplier relationship is the degree of competition between buyers in the market. On the one hand, contracts are more difficult to enforce in a competitive market and hence providing support is more risky (Poulton et al. (2004). On the other hand, Swinnen (2007) argues that farmers that are well-informed about policies and assistance programs of different dairies may also put pressure on their own dairy to introduce these programs. COMPETE measures the number of potential buyers of milk that a farmer has access to. Given the two opposite arguments of Poulton et al. (2004) and Swinnen (2007). The expected effect of COMPETE is ambiguous. Finally, we include two other characteristics of the vertical relationship. Buyer type (TYPE) which is a dummy that takes the value of one if the buyer is a corporate dairy processor and zero if the buyer is a cooperative or an intermediary milk collecting company. FDI is a dummy that takes the value of one if the buyer is either a foreign owned company or the buyer is exporting dairy products. In both instances we expect that internationally focused buyers have 'deep pockets' and therefore have access to the necessary financial resources to provide support programs (Dries and Swinnen 2010; Dries et al. 2009). COLLECT is a dummy that takes the value of 1 if milk is collected by the buyer from the farm instead of through a village collection center and may provide better opportunities for the buyer to monitor and check up on the supplier.

CONTROL includes a number of control variables that may affect the likelihood of access to support programs independently of the characteristics of the vertical relationship. CAPSTOCK refers to the existing capital stock of the farm. Since the main capital asset in Armenian dairy farms are the cattle, we follow the approach of Petrick (2004) by using the number of cows on the farm in the year 2001 as an indicator. It is expected that larger farms have less need for dairy support. On the other hand, larger farms may be in a stronger bargaining position and can negotiate more favourable contract terms. COOPERATE is a dummy that takes the value of one if the farmer indicates that he is cooperating with other farmers to store, market or process milk, to buy inputs, or to engage in lobbying activities. More cooperation between farmers may reduce the need for dairy support programs. On the other hand, more cooperation may also lead to a more dense network that creates more social capital. This may have a positive impact on the likelihood of receiving support.

Table 3 provides summary statistics of the variables included in model (1).
Table 3: Descriptive statistics on model variables

\begin{tabular}{|l|c|c|}
\hline \multicolumn{1}{|c|}{ Variable } & $\begin{array}{c}\text { Share of sample } \\
\text { (dummy) or average } \\
\text { value }\end{array}$ & Standard deviation \\
\hline SUPPORT & 37.3 & - \\
\hline o.w. PLOAN & 35.0 & - \\
\hline o.w. INPUTS & 16.3 & - \\
\hline o.w. PRICE & 46.7 & - \\
\hline o.w. PAYMENT & 87.7 & - \\
\hline INVEST & 72.7 & - \\
\hline INVESTd & 40.0 & 18.3 \\
\hline SHARE & 86.4 & 1.9 \\
\hline COMPETE & 2.0 & - \\
\hline TYPE & 76.0 & - \\
\hline FDI & 22.0 & - \\
\hline COLLECT & 70.0 & 13.24 \\
\hline CAPSTOCK & 8.5 & - \\
\hline COOPERATE & 29.3 & \\
\hline
\end{tabular}

Source: Survey data

\subsection{Determinants of on-farm investments}

The model that we employ to analyse the determinants of on-farm investments and the impact of dairy processors' support measures on investments is based on Elhorst (1993) and Petrick (2004). The model was adapted in line with Dries and Swinnen (2010) to answer the specific research question related to the impact of support programs on investments and to deal with a number of data limitations.

The investment model developed by Elhorst (1993) and applied by Petrick (2004) includes the following independent variables: proxies of the financial situation of the farm (net farm results or solvency indicators); the price of outputs and inputs; capital stock of the farm; the age of the farmer; the presence of a successor; the price of capital goods; the input of family labour. Our empirical model differs from these traditional investment equations in a number of ways. First, we include a series of additional variables to allow a test of our main hypothesis, namely that dairy processors' support programs affect farmers' investment decisions. Next, the cost of capital as well as input and output prices are excluded from the model. Following Petrick (2004) we assume that in our cross-sectional dataset, these prices are equal for all farms and hence can be excluded. Finally, we were unable to include proxies for the farm's financial situation due to data limitations. However, we do include indicators of the capital stock of the farm. We estimate the following empirical model:

INVEST $_{i}=\beta_{\mathbf{0}}+\beta_{\mathbf{1}}$ SUPPORT $_{i}+\beta_{\mathbf{z}}$ CONTROL $_{i}+\varepsilon_{i}$

where INVEST measures farm investment, SUPPORT is a vector of variables measuring support programs from the 
dairy; CONTROL is a vector of control variables; and finally is the error term.

INVEST is a dummy taking the value of one if a household has made an investment in farm assets ${ }^{3}$

in the past five years and it takes the value of zero if no investment was made in the specified period. Dries and Swinnen (2010) have shown that there exists an important correlation between the type of finance (own resources, bank loan, processor loan) and the type of investment (dairyspecific investment, general agricultural investment). We will therefore also estimate the model with the dependent variable, INVESTd, being a dummy that takes the value of one only if an investment was made in a dairy-specific asset. ${ }^{4}$

The first set of variables (SUPPORT) includes several indicators of dairy assistance programs. PLOAN is a dummy that takes the value of one if a supplier is delivering to a dairy company that offers financial assistance, in other words, if the supplier has access to dairy processor loans or credit or bank loan guarantee programs that improve access to external financial resources. INPUTS is a dummy that takes the value of one if the supplier has access to an input supply program from the dairy company and that is zero in the other case. Apart from the direct impact on investments through processor loans, dairy input supply programs are likely to have an indirect impact on suppliers' investments by enhancing the profitability of the farm by lowering input costs, or reducing transaction costs in accessing inputs. Furthermore, bank loan guarantee programs have a potentially important indirect impact on investments by facilitating access to external finance (Dries and Swinnen 2010). We expect PLOAN and INPUTS to have a positive effect on INVEST. Other factors that may cause an indirect impact on the likelihood to invest are the provision of guaranteed prices (PRICE) and prompt payments (PAYMENT). Price guarantees and the absence of payment delays reduce the riskiness of the business environment for the farm operator. As a result, farms may be more inclined to invest than in more uncertain situations.

The control variables (CONTROL) are related to the farm and the farmer. The expected sign of the variable CAPSTOCK depends on the optimal size of the capital stock. A negative sign implies that larger farms are less likely to invest than small farms and consequently, that farm sizes are likely to converge. A positive sign would lead to the opposite conclusion and farm sizes diverge. Apart from efforts to achieve the optimal capital stock, CAPSTOCK may also capture a different effect on investment decisions. Larger farms may benefit from reputation effects and the availability of more collateral. Furthermore, larger farms may benefit from more frequent interactions with the dairy company (Fafchamps 1997; Petersen and Rajan 1997; Johnson et al.
2002; McMillan and Woodruff 1999). This second effect would predict that CAPSTOCK has a positive effect on the likelihood to invest.

COOPERATE is a dummy that takes the value of one if the farmer indicates that he is cooperating with other farmers to store, market or process milk, to buy inputs, or to engage in lobbying activities. We expect that more cooperation leads to a more dense network that creates more social capital. This may have a positive impact on the likelihood to invest.

Table 3 provides summary statistics of the variables included in model (2).

\subsection{Regression results}

Models (1) and (2) are estimated using a logit regression technique. The results for the support relationship are shown in table 4 . Results of the investment model and the dairyspecific investment model are presented in tables 5 and 6 respectively.

Table 4 shows that a more exclusive vertical relationship (i.e. a higher share of milk being sold to the main buyer) increases the likelihood that the milk supplier receives support from the buyer. COMPETE has a significantly negative sign which seems to suggest that milk buyers that operate in a more competitive environment are less likely to offer farm support to their suppliers. The risk of losing suppliers to competitors after support has been provided may be a genuine deterrent for firms to implement farm assistance programs. This finding is in line with Poulton et al. (2004) who find a negative effect of a competitive buyer market on farm support in the African cotton sector. Corporate dairy companies seem to be less inclined to offer support to their suppliers. In other words, farmers supplying cooperative buyers are more likely to benefit from farm assistance. Export-oriented firms and buyers with foreign direct investments are offering more farm support to their suppliers than domestic firms. This finding is in line with the hypothesis that international firms have easier access to the financial resources that are necessary to provide these programs. Finally, having the buyer collect milk at the farm gate reduces a farmer's chances of benefiting from farm support. This result is counterintuitive and requires further investigation. As for the control variables, both CAPSTOCK and COOPERATE have a significantly positive impact on the likelihood of farm support. The former means that larger farms have easier access to support from the buyer. This may indicate that large farms benefit from their stronger bargaining position vis-à-vis the buyer and are able to negotiate more favorable contract terms. Furthermore, transaction costs will be lower if support is given to larger

\footnotetext{
${ }^{3}$ Farm assets include investments in animal housing facilities (building, enlarging or modernizing stalls sheds and herdsman's camps); dairy-specific investments (buying new calves and cows, milk lines, cooling tanks and fodder mixers); and general investments that are not specifically related to milk production such as buying new land, pastures, investments in fences and general agricultural equipment.

${ }^{4}$ Dairy-specific investments include the buying of new calves and cows, milk lines, cooling tanks and fodder mixers.
} 
suppliers as compared to large numbers of small suppliers. The positive effect of cooperation points to the value of being part of a close network.

Table 4: Determinants of farm support programs

(The significance level is indicated as follows: *** $1 \%$; ** 5\%; * 10\%)

\begin{tabular}{|l|c|c|c|}
\hline \multicolumn{1}{|c|}{ SUPPORT } & Coefficient & $\begin{array}{c}\text { Standard } \\
\text { Error }\end{array}$ & Significance \\
\hline SHARE & 0.030 & 0.010 & $* * *$ \\
\hline COMPETE & -0.170 & 0.085 & $* *$ \\
\hline TYPE & -2.376 & 0.373 & $* * *$ \\
\hline FDI & 1.920 & 0.367 & $* * *$ \\
\hline COLLECT & -1.054 & 0.332 & $* * *$ \\
\hline CAPSTOCK & 0.032 & 0.012 & $* *$ \\
\hline COOPERATE & 0.712 & 0.317 & $* *$ \\
\hline Constant & -1.335 & 0.847 & \\
\hline Observations: 300 & & & \\
\hline PseudoR2: 0.243 & & & \\
\hline
\end{tabular}

Source: Own calculations based on survey data

Table 5: Determinants of on-farm investments

(The significance level is indicated as follows: *** 1\%;**5\%; * 10\%)

\begin{tabular}{|l|c|c|c|}
\hline \multicolumn{1}{|c|}{ INVEST } & Coefficient & Standard Error & Significance \\
\hline PLOAN & 1.126 & 0.402 & $* * *$ \\
\hline INPUTS & 1.682 & 0.783 & $* *$ \\
\hline PRICE & 0.959 & 0.302 & $* * *$ \\
\hline PAYMENT & 0.363 & 0.408 & \\
\hline CAPSTOCK & 0.038 & 0.022 & $*$ \\
\hline COOPERATE & 1.059 & 0.377 & $* * *$ \\
\hline Constant & -0.696 & 0.423 & \\
\hline Observations: 300 & & & \\
\hline PseudoR2: 0.169 & & & \\
\hline
\end{tabular}

Source: Own calculations based on survey data

Table 5 (6) presents results on the determinants of (dairyspecific) on-farm investments. We are particularly interested in the effect that different buyer support programs have on the likelihood of farmers to invest. First, access to dairy loans, credit and bank loan guarantees plays a significant role in improving the probability of investments in the Armenian dairy sector. This indicates that access to credit through formal channels (rural finance sector) may be restricted and that dairy loans are crucial to overcome this market imperfection and the sector's financial constraints. Surprisingly, PLOAN is not significant in the dairy-specific investment model. Apart from the direct impact of investments through loans and credit, milk buyers' input supply programs increase the propensity to invest indirectly by enhancing the profitability of the farm by lowering input costs, or reducing transaction costs in accessing inputs. Tables 5 and 6 also provide evidence of the importance of reducing the riskiness of the business environment to stimulate on-farm investments. On the one hand, providing guaranteed prices significantly increases the farmer's likelihood to invest. Furthermore, to stimulate dairy-specific investments it seems crucial to avoid delayed payments. Finally, farm size (CAPSTOCK) plays only a minor role in explaining on-farm investments, while cooperation within a farm network increases the likelihood to invest significantly.

Table 6: Determinants of dairy-specific on-farm investments (The significance level is indicated as follows: $* * * 1 \%$; ** 5\%; *10\%)

\begin{tabular}{|l|c|c|c|}
\hline \multicolumn{1}{|c|}{ INVESTd } & Coefficient & Standard Error & Significance \\
\hline PLOAN & 0.126 & 0.297 & \\
\hline INPUTS & 1.398 & 0.388 & $* * *$ \\
\hline PRICE & 0.157 & 0.256 & \\
\hline PAYMENT & 0.867 & 0.441 & $* *$ \\
\hline CAPSTOCK & 0.014 & 0.011 & \\
\hline COOPERATE & 0.376 & 0.280 & \\
\hline Constant & -1.757 & 0.442 & \\
\hline Observations: 300 & & & \\
\hline PseudoR2: 0.082 & & & \\
\hline
\end{tabular}

Source: Own calculations based on survey data

\section{Concluding remarks}

This paper has looked at the role of vertical relationships between milk producers and milk buyers - and specifically the support programs that buyers have implemented for their suppliers - in explaining on-farm investments in the Armenian dairy sector. Hypotheses are tested using a unique dataset of 300 Armenian commercial rural household farms. The first part of the empirical analysis has linked the specifics of the vertical relationship between the buyer and the supplier to the likelihood of gaining access to farm support programs. The main conclusions are that farmers with a more exclusive relationship to the buyer and farmers that deliver to more internationally oriented buyers (be it exporters or FDI firms) are more likely to receive support. On the other hand, buyers that operate in a more competitive market are less likely to provide support to their suppliers. These findings have interesting policy implications. On the one hand, our results seem to point to the gains that can be made from openness to international firms - who bring in the financial means to provide farm support programs. On the other hand, the negative competition effect may indicate that buyers are limited in their ability to enforce repayment of the provided farm services in an environment where a lot of buyers are competing for the same supply. Policy makers may want to look at ways of improving the enforcement capability of dairy companies under these circumstances.

The second part of the empirical analysis focused on identifying the determinants of on-farm investments, with special emphasis on the impact of buyers' support programs on the likelihood to invest. The results of this analysis 
indicate that dairy support programs play a very important role in stimulating on-farm investments. Farm assistance programs affect investment decisions in several ways. First, dairy loans, credit and loan guarantee programs directly improve farmers' access to financial resources. Second, milk buyers' input supply programs increase the propensity to invest indirectly by enhancing the profitability of the farm by lowering input costs and by reducing transaction costs in accessing inputs. Finally, support programs reduce uncertainty and the riskiness of the business environment by providing guaranteed prices and prompt payments. All these elements have an important effect on the likelihood of investments in the Armenian dairy sector. In conclusion our results show that the linkages between farms and agribusiness have been crucial in stimulating the restructuring process at the farm level.

\section{References}

Dries, L., Germenji, E., Noev, N. and J.F.M. Swinnen (2009). Farmers, Vertical Coordination, and the Restructuring of Dairy Supply Chains in Central and Eastern Europe. World Development, 37(11). 1742-1758.

Dries, L. and J.F.M. Swinnen. (2010). The Impact of Interfirm Relationships on Investment: Evidence from the Polish Dairy Sector. Food Policy, 35. 121-129.
Elhorst, P.J. (1993). The Estimation of Investment Equations at the Farm Level. European Review of Agricultural Economics, 20(2). 167-182.

Fafchamps, M. (1997). Trade Credit in Zimbabwean Manufacturing. World Development, 25(3). 795-815.

Gorton, M., White, J., Dries, L., Ignat, A., Sardaryan, G. and Skripnik, A. (2007). Dairy Farming and Milk Marketing Relationships in the CIS. Eurasian Geography and Economics, 48(6). 733-747.

Johnson, S., McMillan, J. and C. Woodruff (2002). Courts and Relational Contracts. Journal of Law, Economics and Organization, 18. 221-277.

McMillan, J. and C. Woodruff (1999). Interfirm Relationships and Informal Credit in Vietnam. The Quarterly Journal of Economics, 114(4). 1285-1320.

Petrick, M. (2004). Farm Investment, Credit Rationing, and Governmentally Promoted Credit Access in Poland: A CrossSectional Analysis. Food Policy, 29(3). 275-294.

Poulton, C., Dorward, A., Kydd, J. (1998). The revival of smallholder cash crops in Africa: Public and private roles in the provision of finance. Journal of International Development 10. 85-103.

Petersen, M.A. and R.G. Rajan (1997). Trade Credit: Theories and Evidence. The Review of Financial Studies, 10(3). 661-691.

Swinnen, J. (2007). Global supply chains, standards and the poor. CABI Publishing, Oxon, U.K. 
